\title{
EFEITOS DO ESPAÇAMENTO ENTRE LINHAS SOBRE A PRODUÇÃO DE BIOMASSA E CAPTURA DE LUZ EM CULTIVARES DE AMENDOIM COM HÁBITOS DE CRESCIMENTO CONTRASTANTES
}

\author{
Gonzalo Busso ${ }^{1}$; Willians César Carrega ${ }^{2}$; Pedro Luís da C. A. Alves ${ }^{3}$ e Ricardo Javier Haro ${ }^{4}$
} 1Engenheiro agrônomo, gonzabusso@hotmail.com; 2Doutor em Produção Vegetal, FCAV-UNESP, willianscesar@hotmail.com (Apresentador do trabalho); ${ }^{3}$ Docente da FCAV/UNESP, Jaboticabal, SP, plalves@fcav.unesp.br; ${ }^{4}$ Pesquisador Científico do INTA, haro.ricardo@inta.gob.ar

RESUMO: As doenças fúngicas e o atraso na época de semeadura são fatores que podem promovem perdas na produtividade da cultura do amendoim. Contudo, esses fatores podem ser minimizados utilizando-se um manejo adequado. A escolha correta do espaçamento entre linhas pode ser uma alternativa para reduzir os problemas decorrentes de doenças fúngicas. Diante disso, o objetivo do presente estudo foi determinar a resposta de cultivares com hábitos de crescimento contrastantes submetidos a dois espaçamentos entre linhas. Realizou-se um experimento, em campo, na Estação Experimental Agropecuária de Manfredi. O cultivo cresceu sem restrições hídricas mediante a incorporação de laminas de água. A parcela experimental foi composta por quatro linhas de plantas com quinze metros de comprimento cada. Foram avaliados os cultivares Blanco Santa Fe (ereto) e ASEM 484 INTA (rasteiro) submetidos a dois espaçamentos entre linhas de plantio (0,52 e 0,70 m). Aos 50, 72, 86, 99, 119 e 128 dias após a semeadura, foram realizadas amostragens de biomassa e medições de interceptação da radiação. Os resultados foram submetidos a análise de variância e as médias comparadas pelo teste de Tukey a 5\% de probabilidade. Com base nos resultados, constou-se que o espaçamento entre linhas a $52 \mathrm{~cm}$ proporcionou aumento na produção de folhas, biomassa total e vagens apenas para o cultivar Blanco Santa Fe. Para ASEM 484 INTA, não houve incrementos entre os espaçamentos para as variáveis avaliadas. Diante disso, recomenda-se realizar a semeadura no espaçamento entre linhas a $52 \mathrm{~cm}$ para o cultivar Blanco Santa Fe.

Palavras-chave: Arachis hypogaea L.; ASEM 484 INTA; Blanco Santa Fe; doenças; fungos. 
As doenças causadas pelo complexo de fungos de solo e o atraso na semeadura são dois fatores que ocasionam quedas na produtividade do cultivo do amendoim. Diante do crescente aumento de fungos no solo, o cultivo deve migrar para outras regiões onde a pressão dos patógenos são menores. Tem-se observado que genótipos com hábitos de crescimento ereto apresentam menores níveis de infecção em relação aos de hábitos de crescimento rasteiros. Portanto, o uso de cultivares eretos em combinação com adequadas rotações de cultivos, permitirá a semeadura do amendoim por maior número de anos em uma mesma área. No entanto, os cultivares eretos apresentam menor potencial produtivo (HARO et al., 2013) e menor eficiência na interceptação da radiação (HARO et al., 2017), devido a arquitetura das plantas, em comparação aos cultivares rasteiros.

Em relação ao atraso na época de semeadura, as reduções no rendimento são causadas pela exposição do cultivo a um ambiente fototermal de menor qualidade em relação às semeadas mais cedo, principalmente pelas diminuições na radiação (HARO et al., 2007). Diante dos cenários descritos, a prática de redução no espaçamento entre linhas de plantas em combinação com genótipos de distintos hábitos de crescimento, mitigaria as reduções nos rendimentos por meio de aumentos na eficiência no uso da radiação. Contudo, há a carência de evidencias do comportamento dos genótipos atualmente utilizados na região produtora de amendoim na Argentina. Diante disso, o objetivo do presente estudo foi determinar a resposta de cultivares com hábitos de crescimento contrastantes submetidos a espaçamentos entre linhas.

\section{MATERIAL E MÉTODOS}

O experimento foi conduzido em área de campo da Estação Experimental Agropecuária de Manfredi, pertencente ao Instituto Nacional de Tecnologia Agropecuária (INTA), localizada no município de Manfredi, Argentina. A semeadura foi realizada em outubro de 2016, manualmente, com uma densidade de 14 plantas $/ \mathrm{m}^{2}$ e foram realizadas as operações recomendadas para o controle das plantas daninhas, insetos e patógenos.

O cultivo cresceu sem restrições hídricas mediante a incorporação de laminas de água. A parcela experimental foi composta por quatro linhas de plantas com quinze metros de comprimento cada. Foram avaliados os cultivares Blanco Santa Fe (ereto) e ASEM 484 INTA (rasteiro) submetidos a dois espaçamentos entre linhas de semeadura (0,52 m e 0,70 m). Aos 50, 72, 86, 99, 119 e 128 dias após a semeadura, foram realizadas amostragens de biomassa e medições de interceptação da radiação. Para a determinação da biomassa, as plantas de cada tratamento foram 
divididas em folhas, caule (dados não apresentados) e vagens. Para a radiação, as medições foram realizadas com auxílio de um ceptômetro. Os resultados foram submetidos à análise de variância e as médias comparadas pelo teste de Tukey a 5\% de probabilidade.

\section{RESULTADOS E DISCUSSÃO}

Para o cultivar com habito de crescimento ereto (Blanco Santa Fe), verificou-se maiores diferenças entre os parâmetros avaliados. Para esse cultivar (Figura 1), o menor espaçamento entre linhas $(52 \mathrm{~cm})$ proporcionou maior produção de folhas, biomassa total e vagens em relação ao espaçamento a $70 \mathrm{~cm}$, e esse comportamento foi evidenciado desde os estádios iniciais do cultivo e se manteve até a colheita. Contudo, a fração de interceptação da radiação foi igual entre os espaçamentos (52 cm e $70 \mathrm{~cm}$ ). Mesmo sem diferença na interceptação da radiação, acredita-se que no menor espaçamento as plantas apresentam maior eficiência na utilização dessa energia luminosa, uma vez que houve incrementos no acúmulo de massa. Vale ressaltar que o menor espaçamento entre linhas produz um ambiente mais propício para o aproveitamento da água e dos nutrientes disponíveis no solo, incrementando a eficiência dos sistemas produtivos. Além disso, o menor espaçamento também auxilia no manejo do controle de plantas daninhas, em função do rápido fechamento das entre linhas, além de reduzir a erosão por meio da cobertura do solo (CRUZ \& PEREIRA FILHO, 2008).

Para o cultivar rasteiro (ASEM 484 INTA), não se constatou diferenças significativas para os parâmetros avaliados entre os espaçamentos a $52 \mathrm{~cm}$ e $70 \mathrm{~cm}$ (Figura 2). A disposição acentuada dos ramos laterais sobre a área definida entre os dois sulcos (i.e. entre linhas) e as altas taxas de crescimento do cultivar rasteiro (HARO et al., 2007), seriam as causas que impediram as diferenças entre os parâmetros avaliados. 

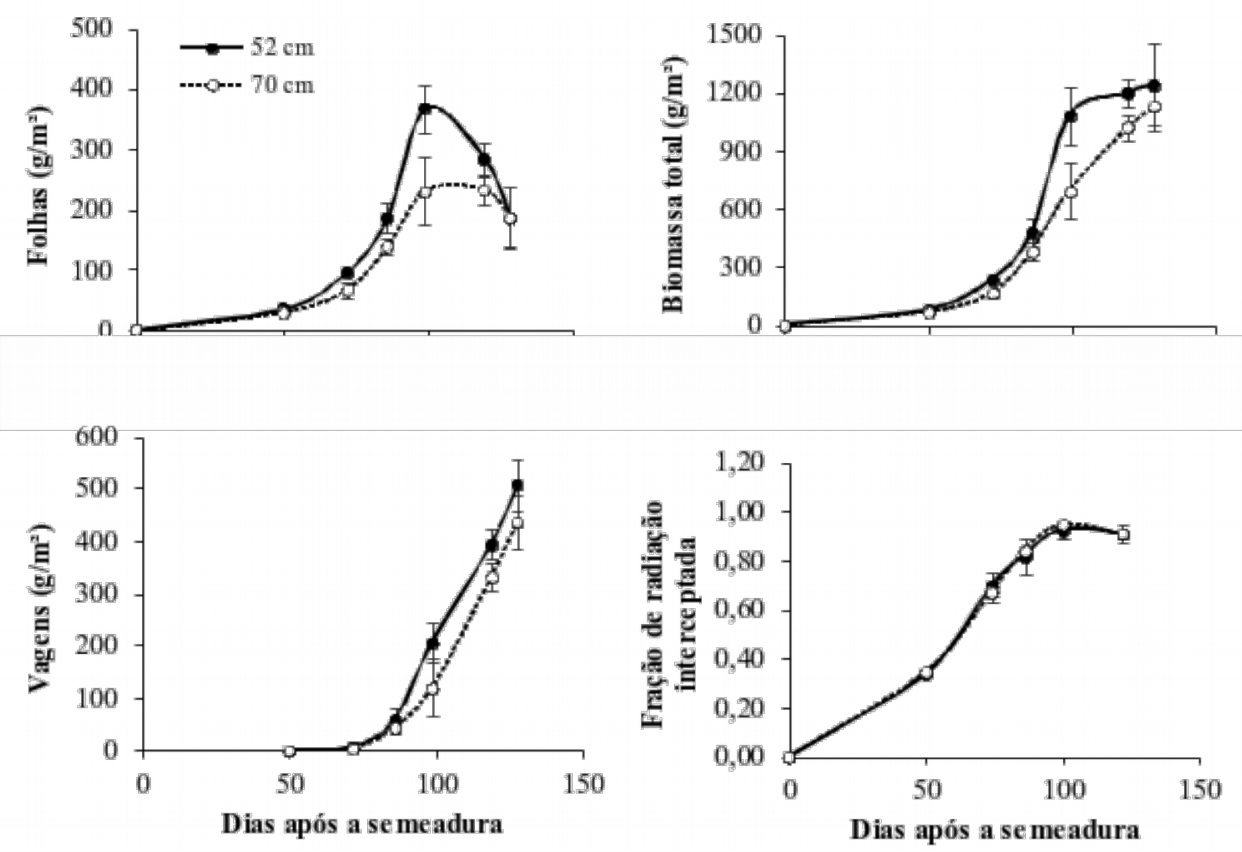

Figura 1. Efeito do espaçamento entre linhas sobre o acúmulo de massa e interceptação da radiação para o cultivar ereto Blanco Santa Fe.
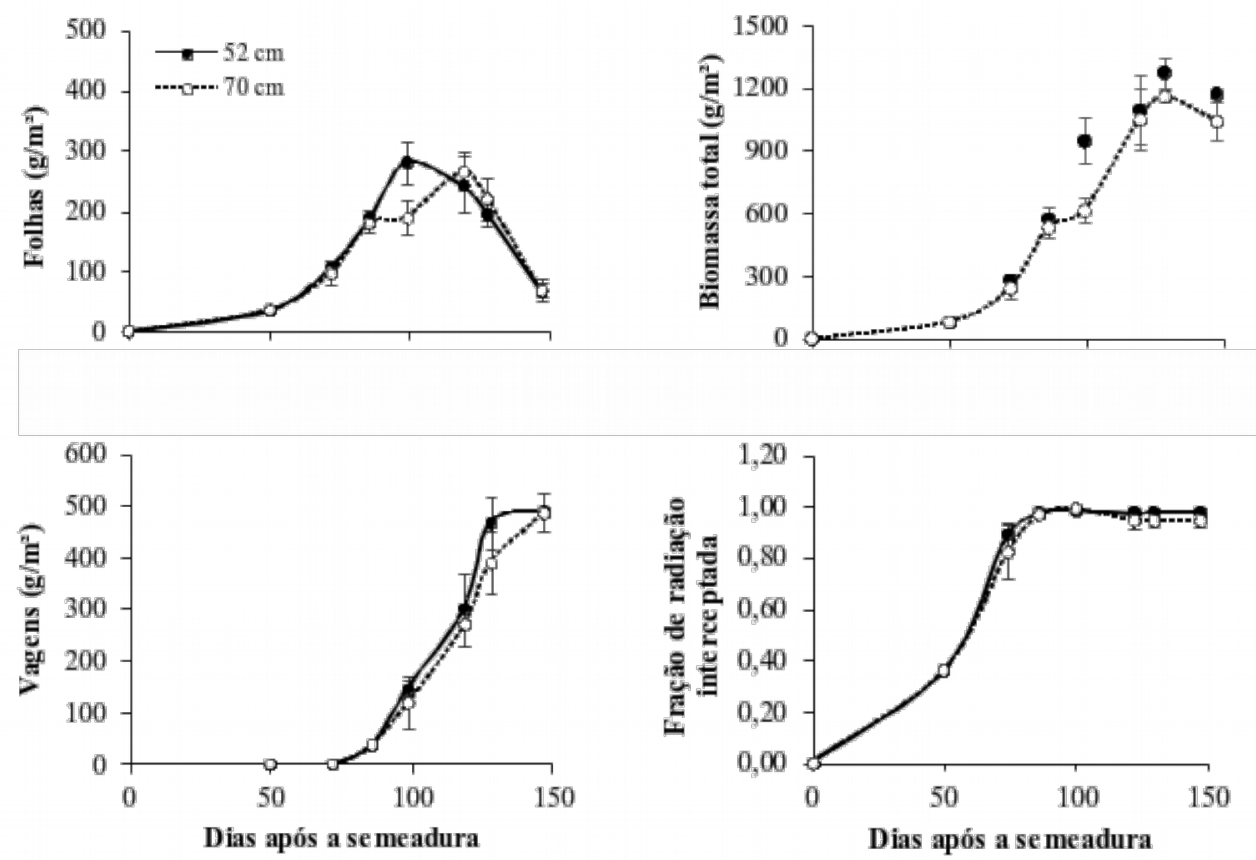

Figura 2. Efeito do espaçamento entre linhas sobre o acúmulo de massa e interceptação da radiação para o cultivar rasteiro ASEM 484 INTA. 


\section{CONCLUSÃO}

O hábito de crescimento definiu as respostas nas variações constatadas entre os espaçamentos entre linhas de plantio. Para o cultivar ereto, a redução no espaçamento para $52 \mathrm{~cm}$ potencializou a produção de folhas, vagens e biomassa total, contudo, não produziu maior interceptação da radiação. Contrariamente, as variações nos espaçamentos para o cultivar com hábito de crescimento rasteiro não produziram diferenças para os parâmetros avaliados nesse estudo.

\section{AGRADECIMENTOS}

Os autores agradecem ao Conselho Nacional de Desenvolvimento Científico e Tecnológico (CNPq), processo $n^{\circ}$ 142462/2013-6 e ao Programa Nacional de Cultivos Industriais (PNIND1108073) de INTA.

\section{REFERÊNCIAS BIBLIOGRÁFICAS}

CRUZ, J. C.; PEREIRA FILHO, I. A. P. A cultura do milho. Sete Lagoas, Embrapa Milho e Sorgo, 2008, $517 \mathrm{p}$.

HARO, R. J.; OTEGUI, M. E.; COLLINO, D. J.; DARDANELLI, J. L. Environmental effects on seed yield determination of irrigated peanut crops: links with radiation use efficiency and crop growth rate. Field Crops Research, v. 103, n. 3, p. 217-228, 2007.

HARO, R. J.; BALDESSARI, J.; OTEGUI, M. E. Genetic improvement of peanut in Argentina between 1948 and 2004: Seed yield and its components. Field Crops Research, v. 149, n. 1, p. 7683, 2013.

HARO, R. J.; BALDESSARI, J.; OTEGUI, M. E. Genetic improvement of peanut in Argentina between 1948 and 2004: Light interception, biomass production and radiation use efficiency. Field Crops Research, v. 204, n. 1, p. 222-228, 2017. 